\title{
Correction to: Stereoselective total synthesis of (-)-pyrenophorol
}

\author{
Dongamanti Ashok ${ }^{1}$ - Sridhar Pervaram ${ }^{2}$. Venkata Ramana Reddy Chittireddy ${ }^{2}$. Sreenivasulu Reddymasu ${ }^{3}$. \\ Naresh Kumar Vuppula ${ }^{4}$
}

Published online: 4 December 2017

(C) Institute of Chemistry, Slovak Academy of Sciences 2017

\section{Correction to: Chem. Pap.}

https://doi.org/10.1007/s11696-017-0331-4

The original version of this article unfortunately contained a mistake.

The affiliation of the second author was incorrect. The correct information is given below.

Department of Chemistry, Jawaharlal Nehru Technological University, Hyderabad, Telangana 500 082, India.

The original article can be found online at https://doi. org/10.1007/s11696-017-0331-4.

Dongamanti Ashok

pervaramsridhar@gmail.com

1 Department of Chemistry, Osmania University, Hyderabad, Telangana 500 007, India

2 Department of Chemistry, Jawaharlal Nehru Technological University, Hyderabad, Telangana 500 082, India

3 Department of Chemistry, University College of Engineering (Autonomous), Jawaharlal Nehru Technological University, Kakinada, Andhra Pradesh 533 003, India

4 Department of Chemistry, Sri Chaitanya P.G College, Godavarikhani, Telangana 505 209, India 